\title{
Article
}

\section{Interactions among Lacosamide and Second-Generation Antiepileptic Drugs in the Tonic-Clonic Seizure Model in Mice}

\author{
Katarzyna Załuska-Ogryzek ${ }^{1} \oplus$, Paweł Marzęda ${ }^{1}$, Paula Wróblewska-Łuczka ${ }^{1} \oplus$, Magdalena Florek-Łuszczki ${ }^{2}$, \\ Zbigniew Plewa ${ }^{3}$, Hubert Bojar ${ }^{4}$, Dorota Zolkowska ${ }^{5}$ and Jarogniew J. Łuszczki ${ }^{1,6, * \mathbb{C}}$
}

1 Department of Pathophysiology, Medical University of Lublin, 20-090 Lublin, Poland; katarzyna.zaluska-ogryzek@umlub.pl (K.Z.-O.); pawel.marzeda@umlub.pl (P.M.); paula.wroblewska-luczka@umlub.pl (P.W.-Ł.)

2 Department of Medical Anthropology, Institute of Rural Health, 20-090 Lublin, Poland; magdalena.florek@wp.pl

3 Department of General, Oncological and Minimally Invasive Surgery, 1st Military Clinical Hospital, 20-048 Lublin, Poland; plewa_z@o2.p1

4 Department of Toxicology and Food Safety, Institute of Rural Health, 20-090 Lublin, Poland; bojar.hubert@imw.lublin.pl

5 Department of Neurology, UC Davis School of Medicine, Sacramento, CA 95816, USA; dzolkowska@gmail.com

6 Isobolographic Analysis Laboratory, Institute of Rural Health, 20-090 Lublin, Poland

* Correspondence: jarogniew.luszczki@umlub.pl; Tel.: +48-81-448-65-03

\section{check for} updates

Citation: Załuska-Ogryzek, K.; Marzęda, P.; Wróblewska-Łuczka, P.; Florek-Łuszczki, M.; Plewa, Z.; Bojar, H.; Zolkowska, D.; Łuszczki, J.J. Interactions among Lacosamide and Second-Generation Antiepileptic Drugs in the Tonic-Clonic Seizure Model in Mice. Int. J. Mol. Sci. 2021, 22, 5537. https://doi.org/10.3390/ ijms22115537

Academic Editor: Stefan Boehm

Received: 20 April 2021

Accepted: 19 May 2021

Published: 24 May 2021

Publisher's Note: MDPI stays neutral with regard to jurisdictional claims in published maps and institutional affiliations.

Copyright: (c) 2021 by the authors. Licensee MDPI, Basel, Switzerland. This article is an open access article distributed under the terms and conditions of the Creative Commons Attribution (CC BY) license (https:// creativecommons.org/licenses/by/ $4.0 /)$.

\begin{abstract}
Combination therapy with two or three antiseizure medications (ASMs) is sometimes a preferred method of treatment in epilepsy patients. (1) Background: To detect the most beneficial combination among three ASMs, a screen test evaluating in vivo interactions with respect to their anticonvulsant properties, was conducted on albino Swiss mice; (2) Methods: Classification of interactions among lacosamide (LCM) and selected second-generation ASMs (lamotrigine (LTG), pregabalin (PGB), oxcarbazepine (OXC), and topiramate (TPM)) was based on the isobolographic analysis in the mouse maximal electroshock-induced seizure (MES) model. Interactions among LCM and second-generation ASMs were visualized using a polygonogram; (3) Results: In the mouse MES model, synergy was observed for the combinations of LCM + TPM + PGB and LCM + OXC + PGB. Additivity was reported for the other combinations tested i.e., LCM + LTG + TPM, LCM + LTG + PGB, $\mathrm{LCM}+\mathrm{LTG}+\mathrm{OXC}$, and LCM + OXC + TPM in this seizure model. No adverse effects associated with triple ASM combinations, containing LCM and second-generation ASMs were observed in mice; (4) Conclusions: The combination of LCM + TPM + PGB was the most beneficial combination among the tested in this study, offering synergistic suppression of tonic-clonic seizures in mice subjected to the MES model. Both the isobolographic analysis and polygonogram method can be recommended for experimental epileptology when classifying interactions among the ASMs.
\end{abstract}

Keywords: drug-drug interaction; antiseizure medication; maximal electroshock-induced seizures; isobolographic analysis; lacosamide; polygonogram

\section{Introduction}

Patients with epilepsy require efficacious treatment with current frontline antiseizure medications (ASMs). Approximately 70\% of epilepsy patients are sufficiently treated with one drug, but the rest of the patients need polytherapy with two or three ASMs [1]. For these patients, physicians try to combine various ASMs so as to provide them with a significant reduction of seizure activity and/or seizure frequency [2]. Despite the progress in clinical epileptology and several novel ASMs licensed recently for the treatment of epilepsy (i.e., perampanel, cenobamate, and ganaxolone) [3-6], there is still no clear definition of refractory epilepsy $[7,8]$. Nevertheless, patients with refractory epilepsy need effective polytherapy with ASMs, but each polytherapy is usually associated with interactions 
among drugs, whose nature may be pharmacodynamic, pharmacokinetic, or mixed [9]. Although physicians can prescribe their patients more than 25 ASMs, they still have no unanimous recommendations on which of these drugs preferentially combine to offer the epileptic patients the best treatment options [10].

At present, several dual and triple combinations of ASMs have gained clinical approval as effective combinations in the treatment of epilepsy [11-13]. However, information about the effective combinations of ASMs has been obtained from some review papers, but there are still no clinical trials evaluating the efficacy of some dual and triple combinations of ASMs. In clinical conditions, it is difficult to directly evaluate the efficacy of the ASMs in various combinations due to a huge number of possible dual and triple combinations of ASMs, the diverse clinical manifestation of seizures, the duration of epilepsy, age of the patients, etc. To help physicians select the proper combinations of ASMs, researchers can test various combinations in preclinical studies and create a ranking list of the most beneficial combinations of ASMs. From a preclinical viewpoint, the best option is to combine ASMs with different molecular targets because the drugs affecting only one target or the same targets may compete with one another and the final effect can be lower than expected [14]. Multi-targeted drugs when combined together can work independently in terms of suppressing seizures, and the drugs in a mixture can be applied in reduced doses, which may contribute to the reduction of the drugs' toxicity [15]. Both maximizing efficacy and minimizing toxicity are the desirable properties of the favorable combinations that can be clinically recommended [16].

To date, several dual and triple combinations of ASMs have been tested in preclinical studies using the maximal electroshock-induced seizure (MES) test, which is thought to be a model of generalized tonic-clonic seizures in mice [17]. Although various ASMs can be theoretically combined together, taking into account their various molecular mechanisms of action, only experimental verification can assess the in vivo efficacy of ASMs in animals. From a theoretical viewpoint, a combination is efficacious (beneficial) if the drugs comprising the combination produce synergistic interaction [18]. In contrast, the least favorable combination is observed if the drugs produce antagonistic interaction. Although the drugs are theoretically selected to constitute beneficial combinations, only the preclinical testing can unequivocally verify these rationally selected drug-drug combinations, confirming finally the exact type of interactions occurring in vivo between the tested drugs [19]. Of course, it is not guaranteed that combinations of ASMs that synergistically work in mice will also work in humans.

In this study, we aimed to classify the interactions for three-drug combinations among 5 ASMs (namely, lacosamide (LCM), lamotrigine (LTG), oxcarbazepine (OXC), pregabalin (PGB), and topiramate (TPM)), so as to select the most beneficial combinations of ASMs, offering synergistic suppression of tonic-clonic seizures in the mouse MES model by means of the isobolographic analysis of interactions accompanied with a polygonogram method. Both, the isobolographic analysis and polygonogram method are applied by researchers to properly classify and visualize interactions occurring among the studied drugs. Understanding which combinations of ASMs are favorable will be essential for selecting the novel therapies for the patients with refractory epilepsy [20]. Of note, the studied 5 ASMs (LCM, LTG, OXC, PGB, and TPM) are effective in suppressing tonic-clonic seizures in both preclinical in vivo studies in mice [17] and clinical settings in humans [21].

\section{Results}

2.1. Anticonvulsant Effects of ASMs When Administered Separately in the Mouse Model of Tonic-Clonic Seizures

All the studied ASMs exerted anticonvulsant effects in the mouse MES model. The log-probit dose-response relationship lines for the tested ASMs were verified in the test for parallelism. All the tested ASMs had their dose-response lines collateral to each other (Supplementary Figure S1). The experimentally derived $\mathrm{ED}_{50}$ values for the ASMs, when injected separately, were calculated from linear log-probit equations (Supplementary Figure S1). 


\subsection{Isobolographic Analysis of Interactions among the Studied ASMs in the Mouse MES Model}

The three-drug mixtures for various triple combinations tested in this study, produced in a dose-dependent manner, the antiseizure effects in the mouse MES model. The experimentally derived $\mathrm{ED}_{50}$ exp values for various triple combinations of ASMs are presented in Table 1.

Table 1. Isobolographic analysis of interactions among three ASMs.

\begin{tabular}{ccccccc}
\hline Drug Combination & $\mathbf{E D}_{\mathbf{5 0} \text { exp }}$ & $\mathbf{n}_{\mathbf{e x p}}$ & $\mathbf{E D}_{\mathbf{5 0} \text { add }}$ & $\mathbf{n}_{\text {add }}$ & $\begin{array}{c}\text { Unpaired } \\
t \text {-Test }\end{array}$ & Interaction \\
\hline LCM + OXC + TPM & $31.06 \pm 2.34$ & 24 & $28.25 \pm 3.37$ & 50 & $\begin{array}{c}\mathrm{t}_{11.99}=0.685 ; \\
p=0.496\end{array}$ & Additivity \\
LCM + LTG + OXC & $7.50 \pm 0.98$ & 32 & $8.97 \pm 0.51$ & 42 & $\begin{array}{c}\mathrm{t}_{47.43}=1.331 ; \\
p=0.190\end{array}$ & Additivity \\
LCM + LTG + PGB & $35.59 \pm 3.86$ & 24 & $45.52 \pm 4.46$ & 42 & $\begin{array}{c}\mathrm{t}_{62.71}=1.684 ; \\
p=0.097 \\
\mathrm{t}_{55.91}=1.716 ; \\
p=0.092\end{array}$ & Additivity \\
LCM + LTG + TPM & $19.06 \pm 2.70$ & 24 & $26.47 \pm 3.37$ & 34 & Additivity \\
LCM + OXC + PGB & $33.04 \pm 4.62^{*}$ & 24 & $47.30 \pm 4.45$ & 58 & $\begin{array}{c}\mathrm{t}_{63.44}=2.223 ; \\
p=0.030 \\
\mathrm{t}_{60.26}=4.022 ; \\
p=0.0002\end{array}$ & Synergy \\
LCM + TPM + PGB & $35.50 \pm 5.28^{* * *}$ & 24 & $64.80 \pm 5.02$ & 50 & Synergy \\
\hline
\end{tabular}

${ }^{*} p<0.05$ and ${ }^{* * *} p<0.001$ vs. the respective $\mathrm{ED}_{50}$ add value. $\mathrm{n}_{\exp }$ - total number of animals from experimental groups at those doses, whose anticonvulsant effects ranged from 4 to 6 probits; $n_{\text {add }}$-total number of animals at doses predicted to be additive, calculated from the equation of additivity.

To display the characteristics of interactions among the tested ASMs, the isobolograms were plotted graphically in the Cartesian plot system. Statistical comparison of ED 50 exp values with $\mathrm{ED}_{50}$ add values revealed that for the combinations of LCM + OXC + TPM and LCM + TPM + PGB, the difference reached significance (at $p<0.05$ and $p<0.001$, respectively), and the observed interaction was synergistic in nature (Table 1 ; Figure 1). For other combinations of ASMs tested, statistical analysis revealed no significance, therefore, the observed interactions were additive in this tonic-clonic seizure model in mice (Table 1 and Figure 1).

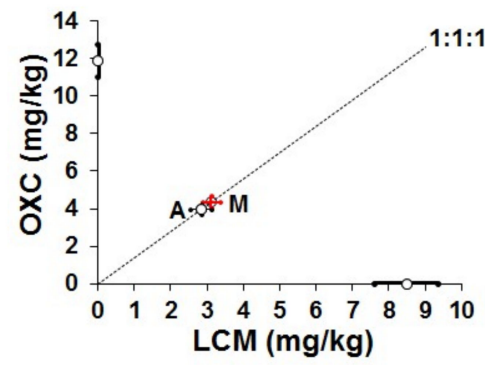

$\operatorname{LCM}(\mathrm{mg} / \mathrm{kg})$

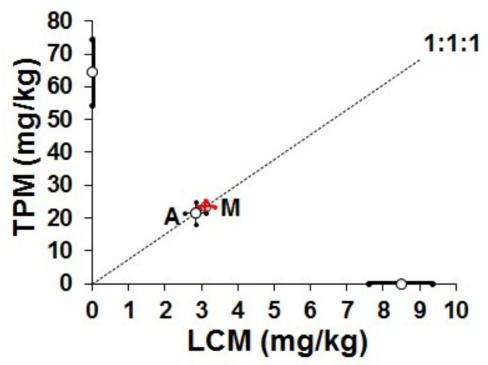

(a)

Figure 1. Cont.

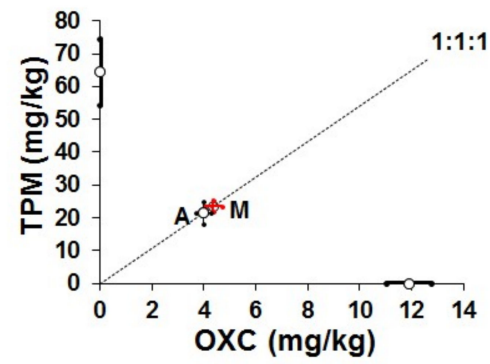



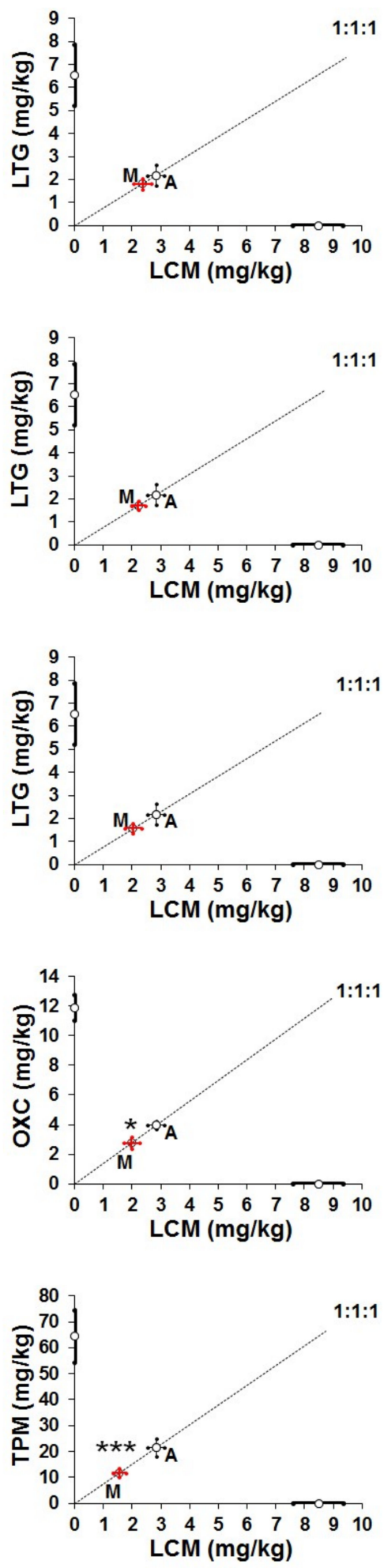

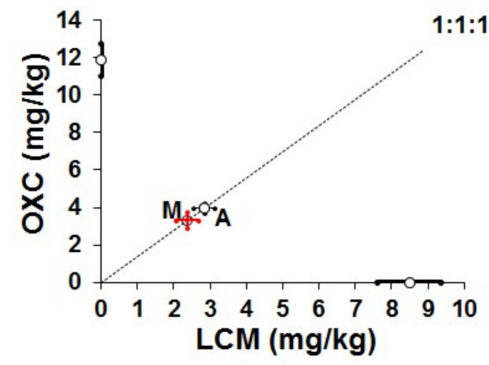

(b)

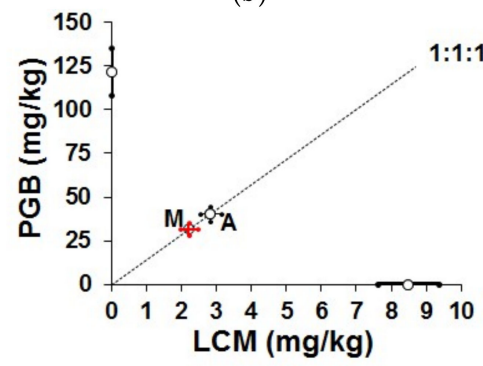

(c)

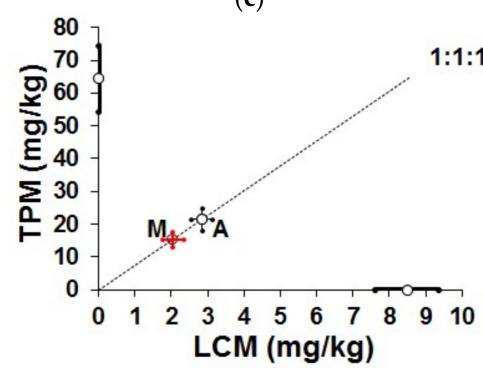

(d)

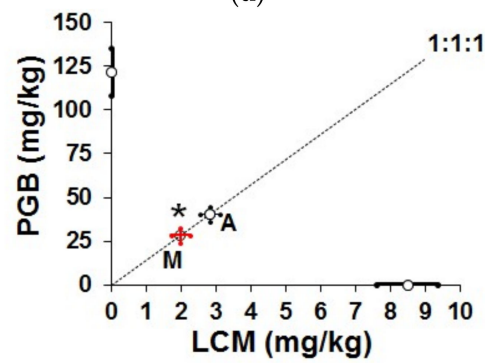

(e)

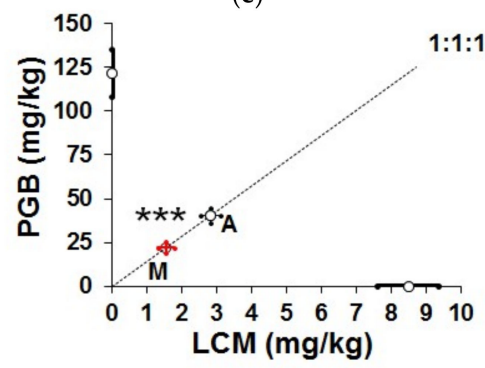

(f)
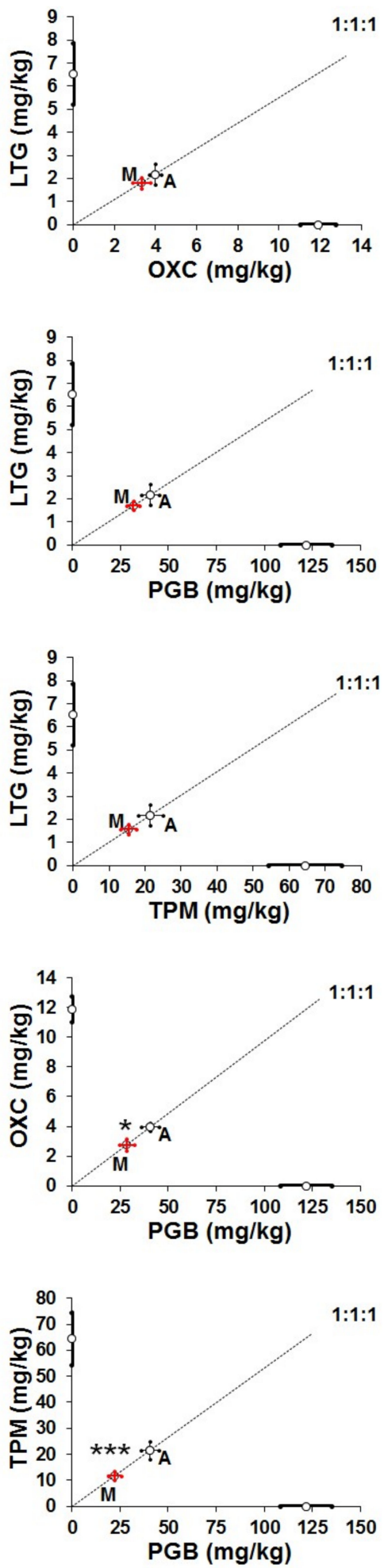

Figure 1. Isobolographic analysis of interactions of various triple ASM combinations: (a) additive interaction for the combination of LCM + OXC + TPM; (b) additive interaction for the combination of LCM + LTG + OXC; (c) additive interaction for the combination of LCM + LTG + PGB; (d) additive interaction for the combination of LCM + LTG + TPM; (e) synergistic interaction for the combination of LCM + OXC + PGB ( ${ }^{*} p<0.05$ - unpaired Student's $t$-test); (f) synergistic interaction for the combination of LCM + TPM + PGB ${ }^{* * *} p<0.001$ unpaired Student's $t$-test). On each graph, point A represents the theoretically calculated additive $\mathrm{ED}_{50}$ add value ( \pm S.E.M. as the error bars), whereas point $\mathrm{M}$ displays the experimentally-derived $\mathrm{ED}_{50} \exp$ value ( \pm S.E.M. as the error bars). 
To visualize all the observed interactions for various three-drug combinations among ASMs in this study, a polygonogram was drawn (Figure 2).

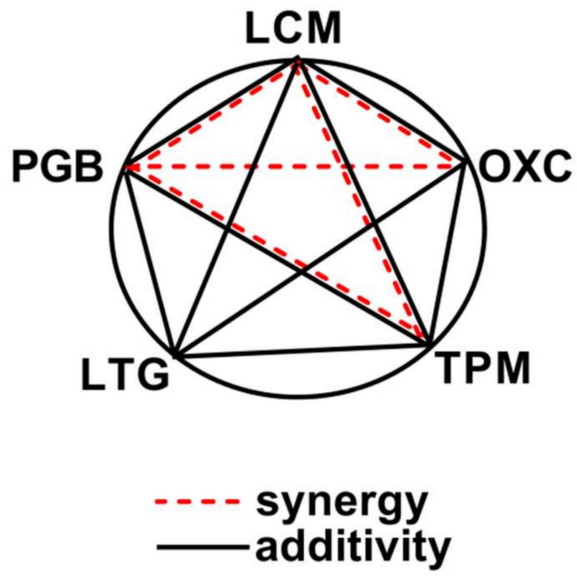

Figure 2. Polygonogram for triple ASM combinations.

\subsection{Interaction Indices for the Tested Triple Combinations of ASMs}

To determine the potency for the observed interactions, the interaction index values were calculated as a ratio of the respective $\mathrm{ED}_{50}$ exp and $\mathrm{ED}_{50}$ add values. The lowest interaction index of 0.55 was determined for the combination of LCM + TPM + PGB (Table 2). In contrast, the highest interaction index value of 1.10 was calculated for the combination of LCM + OXC + TPM (Table 2). The interaction indices allowed for the descending arrangement of the triple ASM combinations (Table 2).

Table 2. Characteristics of interactions for triple combinations of ASMs.

\begin{tabular}{cccc}
\hline Three-Drug Combination & Interaction & Interaction Index & Reference \\
\hline LCM + CBZ + VPA & Antagonism & 1.32 & {$[22]$} \\
LCM + LTG + VPA & Antagonism & 1.27 & {$[23]$} \\
LCM + CBZ + PB & Additivity & 1.18 & {$[24]$} \\
LCM + OXC + TPM & Additivity & 1.10 & this study \\
LCM + LTG + PB & Additivity & 1.07 & {$[25]$} \\
LCM + CBZ + LTG & Additivity & 1.05 & {$[26]$} \\
PB + LTG + OXC & Additivity & 0.94 & {$[17]$} \\
LCM + LTG + OXC & Additivity & 0.84 & this study \\
CBZ + PB + VPA & Additivity & 0.81 & {$[27]$} \\
LCM + LTG + PGB & Additivity & 0.78 & this study \\
LCM + LTG + TPM & Additivity & 0.72 & this study \\
LCM + OXC + PGB & Synergy & 0.70 & this study \\
PB + LTG + PGB & Synergy & 0.64 & {$[17]$} \\
PB + OXC + PGB & Synergy & 0.61 & {$[17]$} \\
PB + OXC + TPM & Synergy & 0.56 & {$[17]$} \\
PB + LTG + TPM & Synergy & 0.56 & this study \\
LCM + TPM + PGB & Synergy & 0.55 & {$[28]$} \\
PB + PHT + PGB & Synergy & 0.53 & {$[29]$} \\
OXC + PGB + TPM & Synergy & 0.51 & {$[17]$} \\
PB + TPM + PGB & Synergy & 0.48 & {$[30]$} \\
CBZ + PB + TPM & Synergy & 0.46 & TH
\end{tabular}

CBZ—carbamazepine; LCM-lacosamide; LTG-lamotrigine; OXC—oxcarbazepine; PB-phenobarbital; PGBpregabalin; PHT_-phenytoin; TPM-topiramate; VPA—valproate.

\subsection{Adverse Effect Potentials of ASMs in Combination in the Rotarod and Grip-Strength Tests} in Mice

All the studied ASMs in three-drug combinations did not significantly impair motor coordination in animals challenged with the rotarod test. In this case, the balancing 
time for animals from the control group did not differ from that for animals receiving the combinations of ASM in doses from the mouse MES model (Table 3). Similarly, the combinations of ASMs did not affect skeletal muscular strength in mice subjected to the grip-strength test. The mean strengths of animals from the control group did not differ considerably from those for the mice receiving ASMs in various triple combinations (Table 3).

Table 3. Potential acute adverse effects in mice subjected to the grip-strength and rotarod tests.

\begin{tabular}{ccc}
\hline Drug Combination & Muscular Strength $(\mathbf{m N} / \mathbf{g})$ & Balancing Time $(\mathbf{s})$ \\
\hline Vehicle + vehicle + vehicle & $39.12 \pm 1.69$ & $120(120 ; 120)$ \\
LCM + OXC + TPM & $38.67 \pm 1.67$ & $120(120 ; 120)$ \\
LCM + LTG + OXC & $39.27 \pm 1.98$ & $120(120 ; 120)$ \\
LCM + LTG + PGB & $38.83 \pm 0.93$ & $120(120 ; 120)$ \\
LCM + LTG + TPM & $41.83 \pm 1.38$ & $120(120 ; 120)$ \\
LCM + OXC + PGB & $39.43 \pm 1.27$ & $120(120 ; 120)$ \\
LCM + TPM + PGB & $41.38 \pm 1.50$ & $120(120 ; 120)$ \\
Statistics & $\mathrm{F}(6 ; 49)=0.698 ; p=0.652$ & KW $=5.093 ; p=0.532$ \\
\hline
\end{tabular}

Each experimental group consisted of 8 mice. LCM-lacosamide; LTG-lamotrigine; OXC-oxcarbazepine; PGB-pregabalin; TPM-topiramate.

\section{Discussion}

Experimental assessment of the anticonvulsant action of three-drug mixtures comprising various combinations of second- and third-generation ASM in preclinical conditions allowed us to select the best combinations with the most beneficial antiseizure action in the mouse MES model. The most favorable triple ASM combination in this study was that for $\mathrm{LCM}+\mathrm{TPM}+\mathrm{PGB}$, which offered the synergistic anticonvulsant effects with an interaction index value of 0.55 . Synergistic interaction among the tested ASMs was also observed for the combination of LCM + PGB + OXC in the mouse MES model with an interaction index value amounting to 0.7 . The other combinations tested in this study were additive with a tendency towards synergy (i.e., LCM + PGB + LTG, LCM + OXC + LTG, and LCM + LTG + TPM) or additive (LCM + OXC + TPM), in this seizure model.

In clinical conditions, polytherapy with ASMs is prescribed usually for patients with refractory epilepsy. If a patient takes a polytherapy with two or three drugs in combination, all the drugs are administered in fully effective doses each. Thus, the patient takes two or three effective drugs in doses providing separately a complete protection from seizures [31]. In the case of the isobolographic analysis, the combined two or three drugs are administered in reduced doses, which are equivalent to one drug used separately $[32,33]$. The isobolographic principle statistically compares doses of drugs in mixture, which experimentally protected the mice from seizures $\left(\mathrm{ED}_{50} \mathrm{exp}\right)$, with doses that are theoretically predicted to be additive $\left(\mathrm{ED}_{50}\right.$ add $)$. Calculation of these additive values for various drug mixtures is based on the equation of mass-action law, whose final effect is always equal to one drug $[32,33]$. According to this equation, doses of drugs in mixture were in a fixed drug dose ratio of 1:1:1 and were substantially reduced, reflecting one $E D_{50}$ value of the ASMs.

Synergistic interactions observed isobolographically in preclinical conditions are always associated with reduced drug doses, which are not expected in clinical settings with triple therapy with ASMs $[34,35]$. We are fully aware of the fact that doses of ASM used in preclinical studies cannot be directly extrapolated to clinical conditions. At present, there is an algorithm allowing for the calculation of the proper dosages of drugs when translating experiments from animals to humans [36]. Generally, the antiseizure effect produced by the combination of ASMs results from the interaction among the ASMs and the activation of their different molecular mechanisms of action. It is expected that the same molecular mechanisms are responsible for the observed interaction in both animal and human studies. On the other hand, clinicians should avoid combining ASMs that produce antagonistic interactions in the mouse MES model. Previously, it has been confirmed that combinations exerting antagonistic interactions in preclinical studies also produced unfavorable effects 
in epilepsy patients. The best examples documenting antagonistic interactions in both preclinical and clinical studies are those for the combinations of LTG with OXC [18] or LTG with CBZ [37], in which the combined effects of LTG with CBZ or OXC were lower than each of the drugs used separately [38-40].

The isobolographic analysis of interaction was predicted to determine pharmacodynamic interactions occurring among the tested drugs. Additionally, to visualize the observed interactions among ASMs, we used the polygonogram method. Although the polygonogram method in the visualization of interactions has been known since 2000 [41], its application in experimental epileptology started two years ago [42]. Of note, the isobologram displays interactions for only one combination of drugs, whereas a polygonogram illustrates interactions for several drugs used in various drug-drug combinations. A polygonogram allows us to quickly assess which of the tested ASM combinations are better than others, with respect to the protection from seizures. This is the reason for presenting the results of this study as a polygonogram and to recommend its application as an obligatory method in this type of research. Of note, researchers using the polygonogram method are forced to perform several experiments in a precisely defined period of time, contributing evidently to the reduction in the number of animals used, which is in agreement with the "3Rs" rule (Replacement, Refinement, Reduction) and ARRIVE guidelines when conducting experiments on animals [43]. This method reduces the total number of laboratory animals used in experimental conditions by using the same available results several times for various calculations (i.e., $\mathrm{ED}_{50}$ values for $\mathrm{ASMs}$ when administered separately). The polygonogram provides also information on several combinations tested in the same experimental conditions [41].

Although several animal models of generalized tonic-clonic seizures are available in preclinical studies [44], the most frequently used model is the MES model in mice [45,46]. Other models of generalized tonic-clonic seizures in mice (i.e., pilocarpine-; N-methylD,L-aspartate-; kainic acid-induced seizures) are specific models of chemically-induced seizures, whose usage is limited and requires some special conditions $[47,48]$. The MES model in mice is easy to reproduce, and each animal subjected to this model develops seizure activity. In contrast, other models are not only time-consuming but also expensive and cost-ineffective, especially, if experiments on animals are performed according to the established protocols [47,48]. Additionally, the MES model in mice is recommended as a screen test for selecting various naturally occurring and newly synthesized compounds with anticonvulsant in vivo properties against tonic-clonic seizures $[49,50]$. In this test, ASMs and their combinations were screened to choose the most effective treatment options that offer suppression of tonic-clonic seizures. This is the main reason to test various threedrug combinations of ASMs in the mouse MES model. On the other hand, in experimental epileptology, there are several animal seizure models reflecting various types of seizures that occur in humans. For instance, pentylenetetrazole-induced seizures reproduce myoclonic seizures and nonconvulsive absence epilepsy in humans; 6-Hz stimulation induced seizures mimic limbic refractory epilepsy in humans; the MES model is thought to be an animal model of generalized tonic-clonic seizures and, to a certain extent, of partial epilepsy in humans $[46,47,51]$. Undoubtedly, the diversity of experimental in vivo models used in preclinical studies affects the evaluation of the anticonvulsant efficacy of some ASMs in combination. Previously, it has been reported that the same combination of two drugs exerted different interactions in various experimental models of epilepsy. More specifically, WIN-55,212-2 mesylate (a non-selective cannabinoid CB1 and CB2 receptor agonist) when combined with phenobarbital, synergistically potentiated the anticonvulsant action of the latter drug in the 6-Hz stimulation induced seizure model in mice [52]. Simultaneously, WIN 55,212-2 mesylate exerted additive interaction with phenobarbital in both the MES and pentylenetetrazole-induced seizure models in mice [53,54]. Similarly, WIN 55,212-2 mesylate synergistically potentiated the antiseizure action of valproate in both, 6- $\mathrm{Hz}$ stimulation and MES models, but it was additive when combined with valproate in the pentylenetetrazole-induced seizure model in mice [52-54]. The diversity of interactions 
observed between WIN 55,212-2 mesylate and two classical ASMs in various experimental models of epilepsy may testify about the model-specific interactions that may occur when combining the ASMs.

Notably, in this study, the interaction index was used as a measure of the potency of interactions for ASM combinations. The lower the interaction index value, the greater synergy is observed in experimental conditions. In this study, statistical analysis of data provided only information on whether or not the analyzed values significantly differed from each other. Even if two values are significantly lower than the theoretically calculated additive values, we cannot precisely indicate which of the tested combinations is better (stronger) than others. In this analysis, the interaction index is the best predictor for characterizing the potency of interactions among ASMs [55,56]. Due to the interaction index values, we can classify interactions more precisely. On the other hand, we are aware of the fact that the classification of interaction based exclusively on border values for synergy, additivity, and antagonism is not precise and without a statistical test it cannot be used alone for the classification of interactions [56,57]. Presently, the application of interaction index values when assessing the potency of interactions among the tested drugs, after confirming the existence of significant difference with one of the commonly used statistical tests (i.e., the unpaired Student's $t$-test), should be recommended in this type of research.

In this study, all pharmacodynamic interactions among newer ASMs were also evaluated with respect to the drugs' propensities to produce side effects that could be potentially harmful to patients in clinical settings. It is noteworthy that doses of ASMs used in triple combinations reflected those doses that protected the animals from seizures. In this study, we assessed the animals' behavior in the grip-strength and rotarod tests. Both, the rotarod and grip-strength tests are commonly used as screen tests in experimental epileptology when evaluating the influence of the tested drugs on animals' behavior, especially, when testing drugs affecting CNS $[55,58,59]$. It is important to note that some of the second-and third-generation ASMs used in this study (i.e., PGB and TPM) produce antinociceptive effects in experimental animals and are used clinically to treat neuropathic pain in suffering patients [60-64]. Additionally, LTG, OXC, and LCM can be used as off-label drugs to treat neuropathic pain, trigeminal neuralgia, and other pain ailments due to their antinociceptive properties $[65,66]$. Therefore, we did not assess the effects of ASMs in combinations on long-term memory processes in mice in the step-through passive avoidance task because this test is based exclusively on nociception produced by an aversive stimulus during the testing procedure and thus, the animals do not experience the aversive stimulus when receiving antinociceptive ASMs. In other words, the observed effects in this test would falsely indicate impaired long-term memory in the mice due to the antinociception exerted by ASMs during the aversive stimulation. The problem of the evaluation of nociceptive reactions in animals receiving ASMs and subjection to the passive avoidance task has been discussed previously $[67,68]$. Evaluation of active learning and memory processes in mice receiving three various ASMs and being subjected to the Y-maze or Morris Water Maze tests needs additional experimental groups of animals to be tested so as to determine the effects of ASMs when used separately and in dual combinations (for more information see: [68-70]). On the other hand, evaluation of the pain threshold in animals receiving the ASMs in combinations and challenged with the step-through passive avoidance task needs also experimental animals [67]. Being aware of the restrictions related with the "3Rs" rule and ARRIVE guidelines [43], when conducting experiments on animals, the evaluation of learning and memory processes in mice was not performed in this study.

Results from the rotarod test indicated that none of the studied ASM combinations considerably altered motor coordination in experimental animals because no significant changes in the animals' balance and coordination were reported in the mice. Additionally, results from the grip-strength test reported that the ASM combinations did not impair skeletal muscular strength in animals. Thus, a lack of any acute adverse effects in animals in the rotarod and grip-strength tests confirmed that the ASM combinations were free of 
any potential side effects. Of note, both behavioral tests used in this study were sensitive enough to detect any subtle changes in experimental animals. As it was documented earlier, the grip-strength test allowed to detect doses of ASM that reduced muscular strength in the mice [58]. Moreover, in the grip-strength test, it was possible to detect drugs that raised the muscular strength in mice (i.e., sildenafil) [71]. The rotarod test also allowed for the determination of doses of ASM that impaired motor coordination and disturbed balance in animals [72,73]. It is worthwhile mentioning that the evaluation of adverse effects was performed after acute (single) administration of ASM in combination.

It should be clearly stated that the interactions among three drugs were evaluated after single drug dosing. Each mixture of three ASMs was administered singly as three separate injections of ASMs. In clinical settings, the ASMs are usually administered chronically. In this experimental model of epilepsy, the mixtures of three drugs were injected from three different syringes in order not to mix the drugs in one syringe before injection. If the drugs are mixed together in one syringe, a pharmaceutical interaction may occur [9,74]. Of note, pharmaceutical interaction is observed if one of the drugs in the mixture inactivates the other drugs before the mixture is injected into a living organism (i.e., outside an organismex vivo). If a pharmaceutical interaction occurs, the mixture produces lower effects than the particular drugs when used singly [57].

To our best knowledge, the combination of LCM + PGB + TPM with an interaction index of 0.55 is the best triple-drug combination observed in preclinical studies in the mouse MES model (Table 2). This combination can be recommended as a treatment option for patients with refractory epilepsy. There is no doubt that we still need combinations of ASMs offering the epileptic patients the effective treatment resulting in a state of seizure freedom. Previously, it has been found that some ASMs in combination produced antagonistic, additive, or synergistic interactions in the mouse MES model (Table 2). Considering the type of interactions occurring in preclinical studies on animals, we can recommend not only the combinations offering synergy in animals, but also those with an additive type of interaction, if the anticonvulsant efficacy of such combinations outweighs the risk of the appearance of adverse effects in epilepsy patients. In this study, it was possible to compare the anticonvulsant action of several triple ASM combinations in the MES model in mice. Due to the interaction index, it was possible to select the most beneficial combinations that could be recommended in clinical settings. In this study, we compared the anticonvulsant properties of triple ASM combinations by arranging them as descending with respect to the observed types of interactions from antagonistic to additive and synergistic (Table 2). All these combinations were tested in preclinical conditions, although the combinations were preferentially selected due to their favorable and theoretically predicted profiles. After conducting experiments on animals, the combinations were finally verified and their profiles were confirmed as synergistic or were classified as additive or antagonistic.

Triple ASM combinations should also be compared to their dual ASM combinations that constitute the tested combinations. In this study, all triple combinations contained LCM as the leading drug added to various dual combinations. Assessment of the anticonvulsant action of dual combinations revealed that PGB combined with LTG, OXC, and TPM exerted additive interaction in the mouse MES model [75]. The combinations of LTG with TPM and OXC with TPM exerted synergistic interaction in the mouse MES model $[18,37]$. Only the combination of LTG with OXC exerted antagonistic interaction in the MES model in mice [18]. Unfortunately, the combinations of LCM with second- and third-generation ASMs have not been tested in the mouse MES model, so it is impossible to present the interaction profiles for the dual combinations comprising of LCM. Considering the abovementioned fact, it can be concluded that the addition of LCM (i.e., the drug which selectively potentiates the slow inactivation of voltage-gated sodium channels in active neurons in the epileptic focus $[76,77])$ to the combination of OXC + TPM changed the interaction type from synergistic (OXC + TPM) to additive (LCM + OXC + TPM). Similarly, the synergistic interaction for the dual combination of LTG + TPM changed to an additive one after adding LCM (LCM + LTG + TPM). In contrast, the antagonistic interaction for OXC + 
LTG transformed to additive after adding LCM (LCM + OXC + LTG) in the mouse MES model. Of note, the synergy observed for the combinations of LCM + PGB + TPM and $\mathrm{LCM}+\mathrm{OXC}+\mathrm{PGB}$ resulted probably from various multi-targeted mechanisms of action of the examined ASMs in combinations. The slow inactivation of voltage-gated sodium channels evoked by LCM [76], accompanied by the blockade of $\alpha 2 \delta$ subunits of calcium channels by PGB [78,79], and the OXC-mediated blockade of calcium and sodium channels in neurons [80], evidently contribute to the synergistic interaction in the mouse MES model. Regarding TPM, the drug with its multi-targeted mechanisms of action related to the blockade of sodium channels, activation of specific GABA-A receptor isoforms, inhibition of AMPA/kainate receptors, and selective inhibition of type II and IV forms of carbonic anhydrase [81-85] can also contribute to the synergistic interaction of the combination of LCM + PGB + TPM in the mouse MES model.

It is important to note that in this study, all ASMs in triple combinations were tested experimentally on adult (8-week-old) animals, but we are aware of the fact that the anticonvulsant effects tested on younger and older animals might theoretically differ, due to different pharmacokinetic parameters related with absorption, distribution, metabolism, and elimination of ASMs, while testing the respective three-drug mixtures. Since different $\mathrm{ED}_{50}$ values are reported for juvenile and adult mice, the interactions occurring among the ASMs in triple combinations might also vary, but this hypothesis needs to be experimentally proved in additional in vivo studies. On the other hand, molecular mechanisms of the anticonvulsant action of ASMs should not differ significantly with respect to the age of the tested animals, and no significant changes in the types of interactions are expected in juvenile and adult animals, especially, if ASMs belong to the second- and third-generation ASMs.

The main limitation in this study is the lack of measurement of concentrations of ASMs. Unfortunately, pharmacokinetic interactions were not verified because the drugs were injected singly. During the single administration of drugs, the activation and/or inhibition of CYP isoenzymes in the liver is less likely. Thus, pharmacokinetic interaction among the tested drugs is also unlikely. Furthermore, the doses of the three drugs in mixture (reflecting the $\mathrm{ED}_{50}$ exp value) were too low, therefore, they were unable to evoke pharmacokinetic interactions. In our previous studies, based on the isobolographic analysis of interactions, we found no pharmacokinetic interactions between ASMs belonging to the first-, second-, and third-generations of ASMs. Besides, the novel ASMs (licensed and approved for the treatment of epilepsy) are designed and created as the drugs with maximal anticonvulsant activity and minimal toxicity, along with their ideal or nearly ideal pharmacokinetic properties. This is the reason not to measure total brain concentrations of ASMs in this study.

\section{Materials and Methods}

\subsection{Animals}

Adult male CD-1 mice (8-week-old, weighing 20 to $27 \mathrm{~g}$ ) were used in this study. The animals were kept in standardized laboratory conditions. Each experimental group contains 8 mice. All experiments run in this study complied with the ARRIVE guidelines, the Guide for the Care and Use of Laboratory Animals of the National Institutes of Health, and the EU Directive 2010/63/EU for animal experiments. All protocols were approved by the Local Ethics Committee for Animal Experimentation at the University of Life Sciences in Lublin, Poland. The total number of mice used in this study was 336 (i.e., 280 mice in the MES model and 56 mice in the grip-strength and rotarod tests).

\subsection{Drugs}

LCM (UCB Pharma, Brussels, Belgium), LTG (Glaxo Wellcome, Kent, UK), OXC (Novartis Pharma AG, Basel, Switzerland), PGB (Pfizer Ltd., Sandwich, Kent, UK), and TPM (Cilag AG, Schaffhausen, Switzerland) were suspended in a 1\% aqueous solution of Tween 80 (Sigma-Aldrich, Poznan, Poland) in distilled water. All the drugs were 
administered systemically (ip) in a volume of $5 \mathrm{~mL} / \mathrm{kg}$ bodyweight. LCM and OXC were injected $30 \mathrm{~min}$, LTG and TPM $60 \mathrm{~min}$, and PGB $120 \mathrm{~min}$ before the MES model and behavioral tests, as recommended elsewhere [86,87]. All experiments were conducted blindly by experienced observers.

\subsection{Maximal Electroshock-Induced Tonic-Clonic Seizures in the Mouse Model}

Tonic-clonic seizure activity in mice was evoked by alternating current $(50 \mathrm{~Hz}, 25 \mathrm{~mA}$, $500 \mathrm{~V}, 0.2 \mathrm{~s}$ stimulus duration) delivered from a rodent shocker using auricular electrodes. Doses of the ASMs when used alone and in triple combinations were transformed logarithmically (log to the base 10), while the antiseizure effects produced by the ASMs in the mice were transformed to probits of response, as recommended elsewhere [88]. Subsequently, from linear log-probit equations, the median effective doses ( $\mathrm{ED}_{50}$ values \pm S.E.M.) of the investigated ASMs (that protected $50 \%$ of the mice from tonic-clonic seizures) were calculated, as it was described earlier [89]. Similarly, the transformation of increasing doses of the three-drug mixtures for the respective combinations (in a constant ratio combination of $1: 1: 1$ ) to the logarithms to the base 10 , and the antiseizure activity produced by the three-drug combinations from the mouse MES model to probits of response, allowed for the calculation of the experimentally-derived median effective doses $\left(E_{50}\right.$ exp values \pm S.E.M.) for the investigated three-drug combinations against tonic-clonic seizures in mice, as described earlier $[17,23,24,26,28,30]$. The number of mice used for the calculation of 5 $E_{50}$ values for LCM, LTG, OXC, PGB, and TPM when administered alone was 136. The number of mice used for the calculation of $\mathrm{ED}_{50}$ exp values for 6 various ASM combinations was 144. Thus, in the mouse MES model we used a total of 280 mice.

\subsection{Isobolographic Analysis of Interactions}

Determination of the parallelism of the dose-response relationship lines for ASMs (when used alone) precedes the isobolographic analysis of interaction, as recommended earlier [90]. Subsequently, the interactions for 6 various three-drug combinations in the mouse MES model were classified isobolographically, as described earlier [91]. For this purpose, the median effective additive doses ( $\mathrm{ED}_{50}$ add values \pm S.E.M.) for three-drug mixtures were calculated from the respective equations of mass-action law, as recommended elsewhere [92]. The $\mathrm{ED}_{50}$ add values are doses of three-drug mixtures, theoretically predicted to protect half of the tested mice from tonic-clonic seizures. Of note, doses of particular ASMs in the mixtures were in the same constant and equal proportion of 1:1:1, as recommended earlier [18,19,30,75,93-100]. The experimentally-derived median effective doses $\left(E_{50}\right.$ exp values \pm S.E.M.) for three-drug mixtures in the fixed proportion of 1:1:1 in the mouse MES model were determined from the log-probit linear regression analysis, as suggested earlier [88]. Isobolographic analysis classified drug-drug interactions as supra-additive (synergistic), additive, and sub-additive (antagonistic) [91]. Detailed information on the isobolographic concepts in experimental epileptology has been previously published $[89,94,101]$. Visualization of all the types of interactions observed for three-drug mixtures in the mouse MES model, was performed by means of polygonogram, as recommended earlier [102,103].

\subsection{Grip-Strength Test}

In the grip-strength test, the effects of 6 various three-drug combinations on skeletal muscular strength in mice were quantified, as recommended elsewhere $[58,104]$. The mice, after receiving the respective three-drug mixtures, were subjected to the measurement of skeletal muscular strength of their forepaws, as described earlier [105-107]. In this test, each mouse was lifted by the tail and placed on the stainless steel grid $(8 \mathrm{~cm} \times 8 \mathrm{~cm})$ connected to the electronic transducer. The animal after grabbing the grid with its forepaws was moved back by the experimenter until the mouse released the grip. The maximal force of the animal's forepaws before releasing the grid was recorded and analyzed as skeletal 
muscular strength (in milliNewton per gram of bodyweight $(\mathrm{mN} / \mathrm{g})$ as means $( \pm$ S.E.M.) of 8 mice).

\subsection{Rotarod Test}

In the rotarod test, the effects of 6 various three-drug combinations on balance and motor coordination in mice were quantified, as recommended elsewhere [72]. The mice, after receiving the respective three-drug mixtures, were subjected to the measurement of balance and motor coordination, as described earlier [108,109]. In this test, each mouse was placed on the rotating cylinders with a constant speed of $6 \mathrm{rpm}$ and the animal has to move and retain in equilibrium for $120 \mathrm{~s}$. In the rotarod test, the time spent by each animal on the rotating cylinder before falling from the rod was measured and analyzed as the balance time (as median time with 25th and 75th percentiles).

\subsection{Statistical Analysis}

The $\mathrm{ED}_{50}$ values for ASMs when used alone and the experimentally-derived $\mathrm{ED}_{50} \exp$ values ( \pm S.E.M.) for various triple ASM combinations from the mouse MES model were calculated by log-probit analysis [88]. Statistical comparison of the $\mathrm{ED}_{50}$ exp values with their respective and theoretically predicted to be additive $\mathrm{ED}_{50}$ add values was performed by means of the unpaired Student's $t$-test, as recommended elsewhere [110]. Statistical comparison of skeletal muscular strengths in animals for the respective ASM combinations was performed with one-way ANOVA, as recommended elsewhere [71]. Statistical comparison of the balance times in animals subjected to the rotarod test was performed with Kruskal-Wallis non-parametric test, as recommended elsewhere [111]. Statistical significance was observed if differences among values were at $p<0.05$. All statistical calculations were performed by means of the GraphPad Prism software (version 7.0 for Windows; GraphPad Software, San Diego, CA, USA).

\section{Conclusions}

Synergistic interactions for the triple combinations of LCM + PGB + TPM and LCM + $\mathrm{OXC}+\mathrm{PGB}$ in the mouse MES model could be recommended for further clinical practice, even if they assume only a certain predictive value. Evaluation and characteristics of interactions among the ASMs should always be performed by means of both, isobolographic analysis and polygonogram, providing finally a simple way to visualize the beneficial ASM combinations. Among the sic combinations tested, only two occurred synergistic in the mouse MES model. The remaining ASM combinations exerted additive interactions in this animal seizure model. Preclinical verification, as an intermediate step in evaluating antiseizure medication of ASM combination, is necessary for selecting the best combinations of ASMs.

Supplementary Materials: The following are available online at https://www.mdpi.com/article/ 10.3390/ijms22115537/s1, Figure S1: Log-probit dose-response relationship lines for ASMs when injected separately.

Author Contributions: Conceptualization, J.J.Ł. and M.F.-Ł.; methodology, P.W.-Ł. and K.Z.-O.; software, P.M. and Z.P.; validation, P.M., Z.P. and H.B.; formal analysis, D.Z. and M.F.-Ł.; investigation, K.Z.-O. and P.W.-Ł.; resources, H.B. and J.J...; data curation, K.Z.-O. and P.W.-Ł.; writing-original draft preparation, M.F.-Ł. and Z.P.; writing—review and editing, D.Z. and J.J.Ł.; visualization, P.W.-Ł. and P.M.; supervision, J.J.Ł.; project administration, M.F.-Ł.; funding acquisition, J.J.Ł. All authors have read and agreed to the published version of the manuscript.

Funding: This research was funded by the Medical University of Lublin, Poland, grant number: DS 474/2018.

Institutional Review Board Statement: The study was conducted according to the ARRIVE guidelines, the Guide for the Care and Use of Laboratory Animals of the National Institutes of Health, and the EU Directive 2010/63/EU for animal experiments, and approved by the Local Ethics Commit- 
tee for Animal Experimentation at the University of Life Sciences in Lublin, Poland (approval no.: 48/2017 and date of approval: 2nd June, 2017).

Informed Consent Statement: Not applicable.

Data Availability Statement: The data presented in this study are available in the article and Supplementary Material here.

Acknowledgments: The authors express their thanks to D.K. for his technical assistance.

Conflicts of Interest: The authors declare no conflict of interest.

\section{References}

1. Kwan, P.; Schachter, S.C.; Brodie, M.J. Drug-resistant epilepsy. N. Engl. J. Med. 2011, 365, 919-926. [CrossRef] [PubMed]

2. Brodie, M.J. Pharmacological treatment of drug-resistant epilepsy in adults: A practical guide. Curr. Neurol. Neurosci. Rep. 2016, 16, 82. [CrossRef]

3. Wheless, J.; Wechsler, R.T.; Lancman, M.; Aboumatar, S.; Patten, A.; Malhotra, M. Perampanel in real-world clinical care of patients with epilepsy: Interim analysis of a phase IV study. Epilepsia Open 2021, 6, 79-89. [CrossRef]

4. Mehndiratta, M.M.; Gulhane, M.; Jabeen, S.A.; Patten, A.; Dash, A.; Malhotra, M. Efficacy and safety of adjunctive perampanel in patients with focal seizures or generalized tonic-clonic seizures: Post hoc analysis of Phase II and Phase III double-blind and open-label extension studies in India. Epilepsia Open 2021, 6, 90-101. [CrossRef] [PubMed]

5. Lattanzi, S.; Riva, A.; Striano, P. Ganaxolone treatment for epilepsy patients: From pharmacology to place in therapy. Expert Rev. Neurother. 2021. [CrossRef] [PubMed]

6. Rosenfeld, W.E.; Nisman, A.; Ferrari, L. Efficacy of adjunctive cenobamate based on number of concomitant antiseizure medications, seizure frequency, and epilepsy duration at baseline: A post-hoc analysis of a randomized clinical study. Epilepsy Res. 2021, 172, 106592. [CrossRef] [PubMed]

7. Janmohamed, M.; Brodie, M.J.; Kwan, P. Pharmacoresistance-Epidemiology, mechanisms, and impact on epilepsy treatment. Neuropharmacology 2020, 168, 107790. [CrossRef] [PubMed]

8. Kwan, P.; Arzimanoglou, A.; Berg, A.T.; Brodie, M.J.; Allen-Hauser, W.; Mathern, G.; Moshe, S.L.; Perucca, E.; Wiebe, S.; French, J. Definition of drug resistant epilepsy: Consensus proposal by the ad hoc Task Force of the ILAE Commission on Therapeutic Strategies. Epilepsia 2010, 51, 1069-1077. [CrossRef] [PubMed]

9. Patsalos, P.N.; Perucca, E. Clinically important drug interactions in epilepsy: General features and interactions between antiepileptic drugs. Lancet Neurol. 2003, 2, 347-356. [CrossRef]

10. Santulli, L.; Coppola, A.; Balestrini, S.; Striano, S. The challenges of treating epilepsy with 25 antiepileptic drugs. Pharmacol. Res. 2016, 107, 211-219. [CrossRef]

11. Stephen, L.J.; Brodie, M.J. Seizure freedom with more than one antiepileptic drug. Seizure 2002, 11, 349-351. [CrossRef] [PubMed]

12. Stephen, L.J.; Brodie, M.J. Antiepileptic drug monotherapy versus polytherapy: Pursuing seizure freedom and tolerability in adults. Curr. Opin. Neurol. 2012, 25, 164-172. [CrossRef] [PubMed]

13. Stephen, L.J.; Forsyth, M.; Kelly, K.; Brodie, M.J. Antiepileptic drug combinations-have newer agents altered clinical outcomes? Epilepsy Res. 2012, 98, 194-198. [CrossRef]

14. Deckers, C.L.; Czuczwar, S.J.; Hekster, Y.A.; Keyser, A.; Kubova, H.; Meinardi, H.; Patsalos, P.N.; Renier, W.O.; van Rijn, C.M. Selection of antiepileptic drug polytherapy based on mechanisms of action: The evidence reviewed. Epilepsia 2000, 41, 1364-1374. [CrossRef]

15. Canevini, M.P.; de Sarro, G.; Galimberti, C.A.; Gatti, G.; Licchetta, L.; Malerba, A.; Muscas, G.; la Neve, A.; Striano, P.; Perucca, E. Relationship between adverse effects of antiepileptic drugs, number of coprescribed drugs, and drug load in a large cohort of consecutive patients with drug-refractory epilepsy. Epilepsia 2010, 51, 797-804. [CrossRef]

16. Rationalizing combination therapies. Nature Med. 2017, 23, 1113. [CrossRef]

17. Łuszczki, J.J.; Podgórska, D.; Kozińska, J.; Jankiewicz, M.; Plewa, Z.; Kominek, M.; Żółkowska, D.; Florek-Łuszczki, M. Polygonogram with isobolographic synergy for three-drug combinations of phenobarbital with second-generation antiepileptic drugs in the tonic-clonic seizure model in mice. Pharmacol. Rep. 2021, 73, 111-121. [CrossRef]

18. Luszczki, J.J.; Czuczwar, S.J. Preclinical profile of combinations of some second-generation antiepileptic drugs: An isobolographic analysis. Epilepsia 2004, 45, 895-907. [CrossRef] [PubMed]

19. Luszczki, J.J.; Ratnaraj, N.; Patsalos, P.N.; Czuczwar, S.J. Pharmacodynamic and pharmacokinetic interaction studies of loreclezole with felbamate, lamotrigine, topiramate, and oxcarbazepine in the mouse maximal electroshock seizure model. Epilepsia 2005, 46, 344-355. [CrossRef]

20. Loscher, W. Single versus combinatorial therapies in status epilepticus: Novel data from preclinical models. Epilepsy Behav. 2015, 49, 20-25. [CrossRef] [PubMed]

21. National Clinical Guideline Centre. National Clinical Guideline Centre. National Institute for Health and Clinical Excellence: Guidance. In The Epilepsies: The Diagnosis and Management of the Epilepsies in Adults and Children in Primary and Secondary Care: Pharmacological Update of Clinical Guideline 20; Royal College of Physicians (UK) National Clinical Guideline Centre: London, UK, 2012. 
22. Kondrat-Wróbel, M.W.; Załuska, K.; Walczak, A.; Panasiuk-Poterek, A.N.; Gut-Lepiech, A.; Wróblewska-Łuczka, P.; Łuszczki, J.J. Antagonistic interaction of lacosamide with carbamazepine and valproate in the mouse tonic-clonic seizure model. Health Prob. Civil. 2019, 13, 92-98. [CrossRef]

23. Luszczki, J.J.; Kondrat-Wróbel, M.; Zagaja, M.; Karwan, S.; Bojar, H.; Plewa, Z.; Florek-Łuszczki, M. Sub-additive (antagonistic) interaction of lacosamide with lamotrigine and valproate in the maximal electroshock-induced seizure model in mice: An isobolographic analysis. Pharmacol. Rep. 2020, 72, 1288-1296. [CrossRef] [PubMed]

24. Kondrat-Wrobel, M.W.; Luszczki, J.J. Interaction of three-drug combination of lacosamide, carbamazepine and phenobarbital in the mouse maximal electroshock-induced seizure model-An isobolographic analysis. Health Probl. Civil. 2016, 10 , 55-61. [CrossRef]

25. Kondrat-Wrobel, M.W.; Luszczki, J.J. Isobolographic additivity among lacosamide, lamotrigine and phenobarbital in the mouse tonic-clonic seizure model. Adv. Clin. Exp. Med. 2018, 27, 881-886. [CrossRef] [PubMed]

26. Kondrat-Wrobel, M.W.; Luszczki, J.J. Additive interaction for three-drug combination of carbamazepine, lacosamide and lamotrigine against maximal electroshock-induced seizures-A type I isobolographic analysis. Eur. J. Clin. Exp. Med. 2017, 15, 303-309. [CrossRef]

27. Załuska, K.; Marzęda, P.; Bojar, H.; Walczak, A.; Chmielewski, J.; Wróblewska-Łuczka, P.; Łuszczki, J.J. Additive suppression of tonic-clonic seizures in mice receiving the combination of carbamazepine, phenobarbital and valproate. J. Pre-Clin. Clin. Res. 2019, 13, 72-75.

28. Luszczki, J.J.; Mazurkiewicz, L.P.; Wroblewska-Luczka, P.; Wlaz, A.; Ossowska, G.; Szpringer, M.; Zolkowska, D.; Florek-Luszczki, M. Combination of phenobarbital with phenytoin and pregabalin produces synergy in the mouse tonic-clonic seizure model: An isobolographic analysis. Epilepsy Res. 2018, 145, 116-122. [CrossRef]

29. Załuska, K.; Kondrat-Wróbel, M.W.; Panasiuk-Poterek, A.N.; Marzęda, P.; Walczak, A.; Wróblewska-Łuczka, P.; Gut-Lepiech, A.; Łuszczki, J.J. Synergy among oxcarbazepine, pregabalin and topiramate in the mouse maximal electroshockinduced seizure test-An isobolographic analysis. J. Pre-Clin. Clin. Res. 2018, 12, 111-116. [CrossRef]

30. Luszczki, J.J. Isobolographic analysis of interaction for three-drug combination of carbamazepine, phenobarbital and topiramate in the mouse maximal electroshock-induced seizure model. Pharmacology 2016, 97, 259-264. [CrossRef] [PubMed]

31. Park, K.M.; Kim, S.E.; Lee, B.I. Antiepileptic drug therapy in patients with drug-resistant epilepsy. J. Epilepsy Res. 2019, 9, 14-26. [CrossRef]

32. Chou, T.C. Theoretical basis, experimental design, and computerized simulation of synergism and antagonism in drug combination studies. Pharmacol. Rev. 2006, 58, 621-681. [CrossRef]

33. Chou, T.C. Drug combination studies and their synergy quantification using the Chou-Talalay method. Cancer Res. 2010, 70, 440-446. [CrossRef]

34. Perucca, E. Overtreatment in epilepsy: Adverse consequences and mechanisms. Epilepsy Res. 2002, 52, 25-33. [CrossRef]

35. Perucca, E.; Kwan, P. Overtreatment in epilepsy: How it occurs and how it can be avoided. CNS Drugs 2005, 19, 897-908. [CrossRef]

36. Nair, A.B.; Jacob, S. A simple practice guide for dose conversion between animals and human. J. Basic Clin. Pharm. 2016, 7, 27-31. [CrossRef]

37. Luszczki, J.J.; Czuczwar, M.; Kis, J.; Krysa, J.; Pasztelan, I.; Swiader, M.; Czuczwar, S.J. Interactions of lamotrigine with topiramate and first-generation antiepileptic drugs in the maximal electroshock test in mice: An isobolographic analysis. Epilepsia 2003, 44, 1003-1013. [CrossRef]

38. Besag, F.M.; Berry, D.J.; Pool, F.; Newbery, J.E.; Subel, B. Carbamazepine toxicity with lamotrigine: Pharmacokinetic or pharmacodynamic interaction? Epilepsia 1998, 39, 183-187. [CrossRef] [PubMed]

39. De Romanis, F.; Sopranzi, N. [Lamotrigine in the therapy of resistant epilepsy]. Clin. Ter. 1999, 150, 279-282. [PubMed]

40. De Romanis, F.; Sopranzi, N. [Lamotrigine: First experience in Italy]. Clin. Ter. 1995, 146, $203-209$.

41. Chang, T.T.; Chou, T.C. Rational approach to the clinical protocol design for drug combinations: A review. Acta Paediatr. Taiwan 2000, 41, 294-302.

42. Luszczki, J.J.; Panasiuk, A.; Zagaja, M.; Karwan, S.; Bojar, H.; Plewa, Z.; Florek-Łuszczki, M. Polygonogram and isobolographic analysis of interactions between various novel antiepileptic drugs in the 6-Hz corneal stimulation-induced seizure model in mice. PLOS ONE 2020, 15, e0234070.

43. Kilkenny, C.; Browne, W.; Cuthill, I.C.; Emerson, M.; Altman, D.G. Animal research: Reporting in vivo experiments: The ARRIVE guidelines. Br. J. Pharmacol. 2010, 160, 1577-1579. [CrossRef]

44. Grone, B.P.; Baraban, S.C. Animal models in epilepsy research: Legacies and new directions. Nat. Neurosci. 2015, 18, 339-343. [CrossRef]

45. Loscher, W. Critical review of current animal models of seizures and epilepsy used in the discovery and development of new antiepileptic drugs. Seizure 2011, 20, 359-368. [CrossRef]

46. Loscher, W.; Fassbender, C.P.; Nolting, B. The role of technical, biological and pharmacological factors in the laboratory evaluation of anticonvulsant drugs. II. Maximal electroshock seizure models. Epilepsy Res. 1991, 8, 79-94. [CrossRef]

47. Kandratavicius, L.; Balista, P.A.; Lopes-Aguiar, C.; Ruggiero, R.N.; Umeoka, E.H.; Garcia-Cairasco, N.; Bueno-Junior, L.S.; Leite, J.P. Animal models of epilepsy: Use and limitations. Neuropsychiatr. Dis. Treat. 2014, 10, 1693-1705. [CrossRef] [PubMed] 
48. Campos, G.; Fortuna, A.; Falcao, A.; Alves, G. In vitro and in vivo experimental models employed in the discovery and development of antiepileptic drugs for pharmacoresistant epilepsy. Epilepsy Res. 2018, 146, 63-86. [CrossRef] [PubMed]

49. Kupferberg, H. Animal models used in the screening of antiepileptic drugs. Epilepsia 2001, 4, 7-12. [CrossRef]

50. Stables, J.P.; Kupferberg, H.J. The NIH Anticonvulsant Drug Development (ADD) Program: Preclinical Anticonvulsant Screening Project; John Libbey: London, UK, 1997; pp. 191-198.

51. Loscher, W.; Honack, D.; Fassbender, C.P.; Nolting, B. The role of technical, biological and pharmacological factors in the laboratory evaluation of anticonvulsant drugs. III. Pentylenetetrazole seizure models. Epilepsy Res. 1991, 8, 171-189. [CrossRef]

52. Florek-Luszczki, M.; Wlaz, A.; Kondrat-Wrobel, M.W.; Tutka, P.; Luszczki, J.J. Effects of WIN 55,212-2 (a non-selective cannabinoid CB1 and CB 2 receptor agonist) on the protective action of various classical antiepileptic drugs in the mouse $6 \mathrm{~Hz}$ psychomotor seizure model. J. Neural Transm. 2014, 121, 707-715. [CrossRef]

53. Luszczki, J.J.; Andres-Mach, M.; Barcicka-Klosowska, B.; Florek-Luszczki, M.; Haratym-Maj, A.; Czuczwar, S.J. Effects of WIN 55,212-2 mesylate (a synthetic cannabinoid) on the protective action of clonazepam, ethosuximide, phenobarbital and valproate against pentylenetetrazole-induced clonic seizures in mice. Prog. Neuropsychopharmacol. Biol. Psychiatry 2011, 35, 1870-1876. [CrossRef]

54. Luszczki, J.J.; Misiuta-Krzesinska, M.; Florek, M.; Tutka, P.; Czuczwar, S.J. Synthetic cannabinoid WIN 55,212-2 mesylate enhances the protective action of four classical antiepileptic drugs against maximal electroshock-induced seizures in mice. Pharmacol. Biochem. Behav. 2011, 98, 261-267. [CrossRef]

55. Loscher, W.; Nolting, B. The role of technical, biological and pharmacological factors in the laboratory evaluation of anticonvulsant drugs. IV. Protective indices. Epilepsy Res. 1991, 9, 1-10. [CrossRef]

56. Gessner, P.K. Isobolographic analysis of interactions: An update on applications and utility. Toxicology 1995, 105, 161-179. [CrossRef]

57. Berenbaum, M.C. What is synergy? Pharmacol. Rev. 1989, 41, 93-141.

58. Zadrozniak, A.; Wojda, E.; Wlaz, A.; Luszczki, J.J. Characterization of acute adverse-effect profiles of selected antiepileptic drugs in the grip-strength test in mice. Pharmacol. Rep. 2009, 61, 737-742. [CrossRef]

59. Porter, R.J.; Kupferberg, H.J. The Anticonvulsant Screening Program of the National Institute of Neurological Disorders and Stroke, NIH: History and contributions to clinical care in the twentieth century and beyond. Neurochem Res. 2017, 42, 1889-1893. [CrossRef]

60. Azmi, S.; ElHadd, K.T.; Nelson, A.; Chapman, A.; Bowling, F.L.; Perumbalath, A.; Lim, J.; Marshall, A.; Malik, R.A.; Alam, U. Pregabalin in the management of painful diabetic neuropathy: A narrative review. Diabetes Ther. 2019, 10, 35-56. [CrossRef]

61. Chincholkar, M. Analgesic mechanisms of gabapentinoids and effects in experimental pain models: A narrative review. Br. J. Anaesth. 2018, 120, 1315-1334. [CrossRef]

62. Derry, S.; Bell, R.F.; Straube, S.; Wiffen, P.J.; Aldington, D.; Moore, R.A. Pregabalin for neuropathic pain in adults. Cochrane Database Syst. Rev. 2019, 1, Cd007076. [CrossRef] [PubMed]

63. Backonja, M.M. Use of anticonvulsants for treatment of neuropathic pain. Neurology 2002, 59 (5 Suppl. 2), S14-S17. [CrossRef]

64. Zhou, M.; Chen, N.; He, L.; Yang, M.; Zhu, C.; Wu, F. Oxcarbazepine for neuropathic pain. Cochrane Database Syst Rev. 2017, 12, Cd007963. [CrossRef]

65. Hearn, L.; Derry, S.; Moore, R.A. Lacosamide for neuropathic pain and fibromyalgia in adults. Cochrane Database Syst. Rev. 2012, 2, Cd009318. [CrossRef]

66. Wiffen, P.J.; Derry, S.; Moore, R.A. Lamotrigine for acute and chronic pain. Cochrane Database Syst Rev. 2011,2, Cd006044.

67. Luszczki, J.J.; Swiader, M.; Parada-Turska, J.; Czuczwar, S.J. Tiagabine synergistically interacts with gabapentin in the electroconvulsive threshold test in mice. Neuropsychopharmacology 2003, 28, 1817-1830. [CrossRef]

68. Luszczki, J.J.; Wojcik-Cwikla, J.; Andres, M.M.; Czuczwar, S.J. Pharmacological and behavioral characteristics of interactions between vigabatrin and conventional antiepileptic drugs in pentylenetetrazole-induced seizures in mice: An isobolographic analysis. Neuropsychopharmacology 2005, 30, 958-973. [CrossRef] [PubMed]

69. Luszczki, J.J.; Sacharuk, A.; Wojciechowska, A.; Andres-Mach, M.M.; Dudra-Jastrzebska, M.; Mohamed, M.; Sawicka, K.M.; Kozinska, J.; Czuczwar, S.J. 7-Nitroindazole enhances dose-dependently the anticonvulsant activities of conventional antiepileptic drugs in the mouse maximal electroshock-induced seizure model. Pharmacol. Rep. 2006, 58, 660-671. [PubMed]

70. Andres-Mach, M.; Szewczyk, A.; Zagaja, M.; Luszczki, J.; Maj, M.; Rola, R.; Abram, M.; Kaminski, K. Evaluation of the impact of compound $\mathrm{C} 11$ a new anticonvulsant candidate on cognitive functions and hippocampal neurogenesis in mouse brain. Neuropharmacology 2020, 163, 107849. [CrossRef] [PubMed]

71. Nieoczym, D.; Luszczki, J.J.; Czuczwar, S.J.; Wlaz, P. Effect of sildenafil on the anticonvulsant action of classical and secondgeneration antiepileptic drugs in maximal electroshock-induced seizures in mice. Epilepsia 2010, 51, 1552-1559. [CrossRef]

72. Luszczki, J.J.; Andres, M.M.; Czuczwar, P.; Cioczek-Czuczwar, A.; Wojcik-Cwikla, J.; Ratnaraj, N.; Patsalos, P.N.; Czuczwar, S.J. Levetiracetam selectively potentiates the acute neurotoxic effects of topiramate and carbamazepine in the rotarod test in mice. Eur. Neuropsychopharmacol. 2005, 15, 609-616. [CrossRef]

73. Luszczki, J.J.; Lepiech, J.; Zagaja, M.; Wroblewska-Luczka, P.; Florek-Luszczki, M.; Bojar, H.; Walczak, A.; Plech, T. Anticonvulsant and neurotoxic effects of a novel 1,2,4-triazole-3-thione derivative (TPF-34) and its isobolographic interaction profile with classical antiepileptic drugs in mice. Pharmacol. Rep. 2020, 72, 87-95. [CrossRef] 
74. Patsalos, P.N.; Perucca, E. Clinically important drug interactions in epilepsy: Interactions between antiepileptic drugs and other drugs. Lancet Neurol. 2003, 2, 473-481. [CrossRef]

75. Luszczki, J.J.; Filip, D.; Czuczwar, S.J. Additive interactions of pregabalin with lamotrigine, oxcarbazepine and topiramate in the mouse maximal electroshock-induced seizure model: A type I isobolographic analysis for non-parallel dose-response relationship curves. Epilepsy Res. 2010, 91, 166-175. [CrossRef]

76. Errington, A.C.; Stohr, T.; Heers, C.; Lees, G. The investigational anticonvulsant lacosamide selectively enhances slow inactivation of voltage-gated sodium channels. Mol. Pharmacol. 2008, 73, 157-169. [CrossRef] [PubMed]

77. Errington, A.C.; Coyne, L.; Stohr, T.; Selve, N.; Lees, G. Seeking a mechanism of action for the novel anticonvulsant lacosamide. Neuropharmacology 2006, 50, 1016-1029. [CrossRef] [PubMed]

78. Calandre, E.P.; Rico-Villademoros, F.; Slim, M. Alpha2delta ligands, gabapentin, pregabalin and mirogabalin: A review of their clinical pharmacology and therapeutic use. Expert Rev. Neurother. 2016, 16, 1263-1277. [CrossRef]

79. Rogawski, M.A.; Bazil, C.W. New molecular targets for antiepileptic drugs: Alpha(2)delta, SV2A, and K(v)7/KCNQ/M potassium channels. Curr. Neurol. Neurosci. Rep. 2008, 8, 345-352. [CrossRef] [PubMed]

80. Brodie, M.J. Sodium channel blockers in the treatment of epilepsy. CNS Drugs 2017, 31, 527-534. [CrossRef] [PubMed]

81. Angehagen, M.; Ben-Menachem, E.; Shank, R.; Ronnback, L.; Hansson, E. Topiramate modulation of kainate-induced calcium currents is inversely related to channel phosphorylation level. J. Neurochem. 2004, 88, 320-325. [CrossRef]

82. Braga, M.F.; Aroniadou-Anderjaska, V.; Li, H.; Rogawski, M.A. Topiramate reduces excitability in the basolateral amygdala by selectively inhibiting GluK1 (GluR5) kainate receptors on interneurons and positively modulating GABAA receptors on principal neurons. J. Pharmacol. Exp. Ther. 2009, 330, 558-566. [CrossRef] [PubMed]

83. Gibbs, J.W., 3rd; Sombati, S.; de Lorenzo, R.J.; Coulter, D.A. Cellular actions of topiramate: Blockade of kainate-evoked inward currents in cultured hippocampal neurons. Epilepsia 2000, 41, S10-S16. [CrossRef] [PubMed]

84. Herrero, A.I.; del Olmo, N.; Gonzalez-Escalada, J.R.; Solis, J.M. Two new actions of topiramate: Inhibition of depolarizing GABA(A)-mediated responses and activation of a potassium conductance. Neuropharmacology 2002, 42, 210-220. [CrossRef]

85. Motaghinejad, M.; Motevalian, M.; Fatima, S.; Beiranvand, T.; Mozaffari, S. Topiramate via NMDA, AMPA/kainate, GABAA and Alpha2 receptors and by modulation of CREB/BDNF and Akt/GSK3 signaling pathway exerts neuroprotective effects against methylphenidate-induced neurotoxicity in rats. J. Neural Transm. 2017, 124, 1369-1387. [CrossRef] [PubMed]

86. Luszczki, J.J.; Wlaz, A.; Karwan, S.; Florek-Luszczki, M.; Czuczwar, S.J. Effects of WIN 55,212-2 mesylate on the anticonvulsant action of lamotrigine, oxcarbazepine, pregabalin and topiramate against maximal electroshock-induced seizures in mice. Eur. $J$. Pharmacol. 2013, 720, 247-254. [CrossRef] [PubMed]

87. Florek-Luszczki, M.; Wlaz, A.; Zagaja, M.; Andres-Mach, M.; Kondrat-Wrobel, M.W.; Luszczki, J.J. Effects of WIN 55,212-2 (a synthetic cannabinoid CB1 and CB2 receptor agonist) on the anticonvulsant activity of various novel antiepileptic drugs against 6 Hz-induced psychomotor seizures in mice. Pharmacol. Biochem. Behav. 2015, 130, 53-58. [CrossRef] [PubMed]

88. Litchfield, J.T., Jr.; Wilcoxon, F. A simplified method of evaluating dose-effect experiments. J. Pharmacol. Exp. Ther 1949, 96, 99-113. [PubMed]

89. Luszczki, J.J.; Ratnaraj, N.; Patsalos, P.N.; Czuczwar, S.J. Isobolographic analysis of interactions between loreclezole and conventional antiepileptic drugs in the mouse maximal electroshock-induced seizure model. Naunyn Schmiedebergs Arch. Pharmacol. 2006, 373, 169-181. [CrossRef]

90. Tallarida, R.J.; Porreca, F.; Cowan, A. Statistical analysis of drug-drug and site-site interactions with isobolograms. Life Sci. 1989, 45, 947-961. [CrossRef]

91. Tallarida, R.J. Drug combinations: Tests and analysis with isoboles. Curr. Protoc. Pharmacol. 2016, 72, 9.19.1-9.19.19. [CrossRef] [PubMed]

92. Loewe, S. The problem of synergism and antagonism of combined drugs. Arzneimittelforschung 1953, 3, 285-290. [PubMed]

93. Luszczki, J.J.; Andres, M.M.; Czuczwar, S.J. Synergistic interaction of gabapentin and oxcarbazepine in the mouse maximal electroshock seizure model-An isobolographic analysis. Eur. J. Pharmacol. 2005, 515, 54-61. [CrossRef]

94. Luszczki, J.J.; Antkiewicz-Michaluk, L.; Raszewski, G.; Czuczwar, S.J. Interactions of 1-methyl-1,2,3,4-tetrahydroisoquinoline with lamotrigine, oxcarbazepine, pregabalin, and topiramate in the mouse maximal electroshock-induced seizure model: A type I isobolographic analysis. Epilepsy Res. 2010, 89, 207-219. [CrossRef]

95. Luszczki, J.J.; Czuczwar, S.J. Isobolographic characterization of interactions between vigabatrin and tiagabine in two experimental models of epilepsy. Prog. Neuropsychopharmacol. Biol. Psychiatry 2007, 31, 529-538. [CrossRef] [PubMed]

96. Luszczki, J.J.; Czuczwar, S.J. Biphasic characteristic of interactions between stiripentol and carbamazepine in the mouse maximal electroshock-induced seizure model: A three-dimensional isobolographic analysis. Naunyn Schmiedebergs Arch. Pharmacol. 2006, 374, 51-64. [CrossRef]

97. Luszczki, J.J.; Czuczwar, S.J. Interaction between lamotrigine and felbamate in the maximal electroshock-induced seizures in mice: An isobolographic analysis. Eur. Neuropsychopharmacol. 2005, 15, 133-142. [CrossRef] [PubMed]

98. Luszczki, J.J.; Czuczwar, S.J. Three-dimensional isobolographic analysis of interactions between lamotrigine and clonazepam in maximal electroshock-induced seizures in mice. Naunyn Schmiedebergs Arch. Pharmacol. 2004, 370, 369-380. [CrossRef]

99. Luszczki, J.J.; Florek-Luszczki, M. Synergistic interaction of pregabalin with the synthetic cannabinoid WIN 55,212-2 mesylate in the hot-plate test in mice: An isobolographic analysis. Pharmacol. Rep. 2012, 64, 723-732. [CrossRef] 
100. Luszczki, J.J.; Ratnaraj, N.; Patsalos, P.N.; Czuczwar, S.J. Isobolographic and behavioral characterizations of interactions between vigabatrin and gabapentin in two experimental models of epilepsy. Eur. J. Pharmacol. 2008, 595, 13-21. [CrossRef]

101. Luszczki, J.J.; Borowicz, K.K.; Swiader, M.; Czuczwar, S.J. Interactions between oxcarbazepine and conventional antiepileptic drugs in the maximal electroshock test in mice: An isobolographic analysis. Epilepsia 2003, 44, 489-499. [CrossRef]

102. Chou, T.C. Preclinical versus clinical drug combination studies. Leuk. Lymphoma 2008, 49, 2059-2080. [CrossRef]

103. Chou, T.C.; Talalay, P. Quantitative analysis of dose-effect relationships: The combined effects of multiple drugs or enzyme inhibitors. Adv. Enzyme Regul. 1984, 22, 27-55. [CrossRef]

104. Meyer, O.A.; Tilson, H.A.; Byrd, W.C.; Riley, M.T. A method for the routine assessment of fore- and hindlimb grip strength of rats and mice. Neurobehav. Toxicol. 1979, 1, 233-236.

105. Luszczki, J.J.; Czuczwar, P.; Cioczek-Czuczwar, A.; Czuczwar, S.J. Arachidonyl-2'-chloroethylamide, a highly selective cannabinoid CB1 receptor agonist, enhances the anticonvulsant action of valproate in the mouse maximal electroshock-induced seizure model. Eur. J. Pharmacol. 2006, 547, 65-74. [CrossRef] [PubMed]

106. Luszczki, J.J.; Czuczwar, P.; Cioczek-Czuczwar, A.; Dudra-Jastrzebska, M.; Andres-Mach, M.; Czuczwar, S.J. Effect of arachidonyl2'-chloroethylamide, a selective cannabinoid CB1 receptor agonist, on the protective action of the various antiepileptic drugs in the mouse maximal electroshock-induced seizure model. Prog. Neuropsychopharmacol. Biol. Psychiatry 2010, 34, 18-25. [CrossRef]

107. Andres-Mach, M.; Zolkowska, D.; Barcicka-Klosowska, B.; Haratym-Maj, A.; Florek-Luszczki, M.; Luszczki, J.J. Effect of ACEA-A selective cannabinoid CB1 receptor agonist on the protective action of different antiepileptic drugs in the mouse pentylenetetrazole-induced seizure model. Prog. Neuropsychopharmacol. Biol. Psychiatry 2012, 39, 301-309. [CrossRef] [PubMed]

108. Carter, R.J.; Morton, J.; Dunnett, S.B. Motor coordination and balance in rodents. Curr. Protoc. Neurosci. 2001. [CrossRef] [PubMed]

109. Deacon, R.M. Measuring motor coordination in mice. J. Vis. Exp. 2013, 75, e2609. [CrossRef] [PubMed]

110. Tallarida, R.J. Quantitative methods for assessing drug synergism. Genes Cancer 2011, 2, 1003-1008. [CrossRef]

111. Yu, Z.; Wenyan, T.; Xuewen, S.; Baixiang, D.; Qian, W.; Zhaoyan, W.; Yinxiang, Y.; Suqing, Q.; Zuo, L. Immunological effects of the intraparenchymal administration of allogeneic and autologous adipose-derived mesenchymal stem cells after the acute phase of middle cerebral artery occlusion in rats. J. Transl. Med. 2018, 16, 339. [CrossRef] 